\title{
New Perspectives in the Management of Mild to Moderate Asthma in Children
} Hacer Ilbilge Ertoy Karagol (D)
Arzu Bakirtas (D)

Department of Pediatric Allergy and Asthma, Gazi University School of Medicine, Ankara, Turkey
Correspondence: Hacer Ilbilge Ertoy Karagol

Department of Pediatric Allergy and

Asthma, Gazi University School of

Medicine, Besevler, Ankara, 06510, Turkey

Tel +903122025129

Fax +903122129016

Email theilbilge@yahoo.com.au
This article was published in the following Dove Press journal:

Journal of Asthma and Allergy

\begin{abstract}
Mild to moderate asthma makes up the greatest proportion of all asthma severities in childhood. Children who are treated with steps 1-2 are defined as having mild asthma and step 3 as having moderate asthma, according to the guidelines. Although many studies focused on the management of severe asthma over the last decade, there have also been important changes and improvements in the management of mild to moderate asthma. In this article, new perspectives in the management of children with mild to moderate asthma will be reviewed and compared according to the two major guidelines.
\end{abstract}

Keywords: asthma, mild, moderate, long-acting inhaled bronchodilators, treatment

Mild to moderate asthma is defined according to the frequency of symptoms and risk of exacerbations in the Global Initiative for Asthma Guideline (GINA) and National Asthma Education and Prevention Program Expert Panel Report 3., Another definition of mild to moderate asthma in the GINA guidelines is non-severe asthma which can be controlled by steps $1-3$ treatment. ${ }^{1}$ Although mild to moderate asthma constitutes the majority of childhood asthma, it is also a heterogeneous group as severe asthma. ${ }^{3}$ Data on phenotypic characterization of mild to moderate asthma is limited.,.$^{3,4}$ Predictors of poor outcomes such as exacerbations or persistent airflow obstruction are still largely unknown. ${ }^{3}$ Treatment options and studies on predictors of response to treatments in mild to moderate asthma are very limited. ${ }^{5}$ Besides, mild asthma is no longer regarded as an easy condition to manage considering the severe exacerbation risk $(0.12$ and 0.77 severe exacerbations per patient per year). ${ }^{6}$ Furthermore, compliance to regular controller medication is worse in mild, but also in the moderate spectrum of, asthma compared to severe asthma, that may be the main reason of severe exacerbations in these groups. $^{7}$

The risk of severe exacerbation even in the mildest spectrum of asthma led to major changes in the management of this category. As sufficient data was accumulated, the use of a combination of inhaled corticosteroid (ICS)formoterol in a single inhaler as maintenance and reliever treatment and a low dose ICS taken whenever short-acting beta ${ }_{2}$-agonist (SABA) is taken was recommended in an effort to overcome the problems of compliance and severe exacerbation. Additionally, specific allergen immunotherapy is suggested as an add-on treatment in selected allergic asthmatic patients. Lastly, the guidelines included the Food and Drug Administration's announcement about the 
requirement of a boxed warning about the risk of serious mental health adverse effects with montelukast. ${ }^{8}$

In this review, new perspectives in the management of children with mild to moderate asthma will be discussed and compared according to treatment steps and age groups in GINA ${ }^{1,9}$ and National Heart, Lung, and Blood Institute $(\mathrm{NHBLI})^{10}$ guidelines.

\section{Step I}

Step 1 treatment is recommended for mild intermittent asthma. In this group, symptoms are less than two days a month with no risk factors for future exacerbations according to GINA guidelines. ${ }^{9}$ The new treatment recommendations in GINA and NHBLI asthma guidelines at steps 1-3 are given in a table for each age group (Table 1).

\section{Teens ( $\geq 12$ Years Old)}

There are new recommendations for "preferred controller and reliever options" in adolescents $\geq 12$ years old with asthma in GINA guideline. ${ }^{1,9}$ SABA-only treatment is no longer recommended for adolescents with mild asthma because of the risk of death ${ }^{11}$ and urgent health care utilization $^{12}$ related to asthma, although they may have good control of their asthma symptoms. ${ }^{13}$ As-needed, a low dose ICS-formoterol combination is both the preferred controller and reliever treatment options in this step. The basis for these treatment options comes from indirect evidence (therefore classified as evidence B) provided by two randomized controlled trials (RCTs) where adolescents $\geq 12$ years are also included with adults. ${ }^{14,15}$ In the first study, it was demonstrated that the as-needed budesonide-formoterol group was superior to the as-needed

Table I New Recommendations in the Treatment of Mild to Moderate Asthma According to the GINA and NHLBI Guidelines

\begin{tabular}{|c|c|c|c|}
\hline & & GINA & NHLBI \\
\hline \multirow[t]{4}{*}{ Step I } & Teens & As-needed low dose ICS-formoterol* & \multirow[t]{2}{*}{ No new recommendations } \\
\hline & & Low dose ICS taken whenever SABA taken ${ }^{\#}$ & \\
\hline & $6-11$ years old & Low dose ICS taken whenever SABA taken ${ }^{\#}$ & No new recommendations \\
\hline & Preschool age & No new recommendations & $\begin{array}{l}\text { As-needed SABA and add short course daily ICS at the } \\
\text { start of RTI }\end{array}$ \\
\hline \multirow[t]{4}{*}{ Step 2} & \multirow[t]{2}{*}{ Teens } & \multirow[t]{2}{*}{ As-needed low dose ICS-formoterol ${ }^{\dagger}$} & Low dose ICS taken whenever SABA taken ${ }^{\dagger}$ \\
\hline & & & $\begin{array}{l}\text { **SCIT as adjunct treatment to standard } \\
\text { pharmacotherapy }\end{array}$ \\
\hline & $6-11$ years old & Low dose ICS taken whenever SABA taken ${ }^{\#}$ & * SCIT as adjunct treatment to standard pharmacotherapy \\
\hline & Preschool age & No new recommendations & No new recommendations \\
\hline \multirow[t]{6}{*}{ Step 3} & \multirow[t]{2}{*}{ Teens } & Daily and as-needed low-dose ICS-formoterol ${ }^{\ddagger}$ & Daily and as-needed low-dose ICS-formoterol ${ }^{\ddagger}$ \\
\hline & & $\begin{array}{l}\text { **Consider adding HDM SLIT for sensitized patients with } \\
\text { allergic rhinitis and FEV }>70 \%\end{array}$ & $\begin{array}{l}\text { **SCIT as adjunct treatment to standard } \\
\text { pharmacotherapy }\end{array}$ \\
\hline & \multirow[t]{2}{*}{$6-11$ years old } & \multirow[t]{2}{*}{ No new recommendations } & Daily and as-needed low-dose ICS-formoterol* \\
\hline & & & $\begin{array}{l}\text { **SCIT as adjunct treatment to standard } \\
\text { pharmacotherapy (for } 5-11 \text { year olds) }\end{array}$ \\
\hline & \multirow[t]{2}{*}{ Preschool age } & \multirow[t]{2}{*}{ No new recommendations } & $\begin{array}{l}\text { Low dose ICS-LABA and as-needed SABA (for } \leq 3 \text { years } \\
\text { old)* }\end{array}$ \\
\hline & & & $\begin{array}{l}\text { Daily and as-needed low dose ICS-formoterol (for } 4 \text { years } \\
\text { old)* }\end{array}$ \\
\hline
\end{tabular}

Notes: *Preferred controller and reliever treatment option in this age group. ${ }^{\#}$ Other controller option in this age group. ${ }^{\dagger}$ Second preferred controller and reliever treatment option in this age group. ${ }^{\ddagger}$ Low dose ICS-formoterol is the reliever only for patients prescribed budesonide-formoterol maintenance and reliever therapy. **Conditional recommendation. Data from Global Initiative for Asthma (GINA) ${ }^{1,9}$ and National Asthma Education and National Heart, Lung, and Blood Institute, National Institutes of Health. ${ }^{10}$

Abbreviations: ICS, inhaled corticosteroid; LABA, long-acting beta ${ }_{2}$-agonist; SABA, short-acting beta ${ }_{2}$-agonist; RTI, respiratory tract infection; SCIT, subcutaneous allergen immunotherapy; SLIT, sublingual allergen immunotherapy; HDM, house dust mite. 
terbutaline group when considering symptom control. In addition, exacerbation rates with as-needed budesonideformoterol and regular daily budesonide regimens were similar and lower compared to terbutaline group. ${ }^{14}$ In the second study, the annual rate of severe exacerbation was not inferior in the group using as-needed budesonideformoterol than daily regular budesonide maintenance therapy. ${ }^{15}$

"Other controller option" newly recommended in step 1 for adolescents $\geq 12$ years is low dose ICS taken whenever SABA taken. This option depends on indirect evidence from studies that included patients eligible for step 2 treatment separate from or in combination with ICS and SABA inhalers. ${ }^{16,17}$ This may be an option, especially in those who have difficulty in adhering to daily low dose ICS therapy and in mild patients with infrequent symptoms, while decreasing future risks of exacerbations compared to as-needed SABA-only treatment. In addition, it may be an alternative option for countries where fixed budesonide-formoterol or beclomethasone-formoterol combinations are either not available or affordable. On the other hand, there is no new recommendation at this step for adolescents in the NHLBI guidelines. ${ }^{10}$

\section{6 - II-Year-Old Children}

There are two new options presented under "other controller options" in the 2019 and 2020 revisions of the GINA guidelines: low dose ICS taken whenever SABA is taken or daily low dose ICS. ${ }^{1,9}$ These recommendations based on the data from an RCT involving children aged $\geq 6$ (TREXA study), ${ }^{16}$ and a real-world open-label trial involving African-American children aged 6-17 years by Sumino et al. ${ }^{17}$ In the TREXA trial, rescue beclomethasone (as-needed beclometasone with SABA in separate inhalers) was shown to decrease the risk of exacerbations by more than a third, compared to SABA only treatment. ${ }^{16}$ In the other study, it was shown that asthma control and exacerbations were no different in those who use as-needed beclometasone with SABA from those who use beclometasone on a daily basis. ${ }^{17}$ These two studies showed that rescue ICS with SABA in separate inhalers resulted in lower ICS exposure ${ }^{17}$ and growth impairment, ${ }^{16}$ compared to daily low dose ICS which preserves its place as the "other controller option" in the GINA guideline at this step. ${ }^{1}$ There is no new recommendation for 6- to 11-year-old children in the NHBLI guidelines. ${ }^{10}$

\section{Preschool Children ( $\leq 5$ Years Old)}

The evidence is accumulating much more slowly in this age group because of the difficulty of definite asthma diagnosis, transition between symptom patterns and challenges of planning research compared to older age groups. There is still no change in either preferred controller or reliever options in step 1 in GINA 2020 guideline. $^{1}$ Nevertheless, a trial of controller treatment who use SABA more than twice a week in a month is recommended by expert opinion under "preferred options"in the GINA guideline since the 2019 update. ${ }^{9}$ The use of intermittent high dose ICS with as-needed SABA for intermittent viral induced wheezing attacks with no interval symptoms, is recommended as the "other option" in the GINA guidelines. ${ }^{1,9}$ This is a conditional recommendation for 0- to 4-year-old children with recurrent wheezing in the NHLBI 2020 asthma guidelines and it is suggested it should be started at the onset of an apparent respiratory tract infection. ${ }^{10}$ There are three RCTs referred to for this recommendation. $^{18-20}$ two of them also assessed growth. ${ }^{18,19}$ One of them found a $5 \%$ lower gain in height ${ }^{19}$ and the other did not find an effect on linear growth. ${ }^{18}$ Therefore clinicians are recommended to discuss this issue with parents and make close monitorization of growth if they decide to use this intermittent treatment regimen. ${ }^{10}$

\section{Step 2}

Step 2 asthma treatment is recommended for mild persistent asthma patients whose symptoms are more than 2 days a month but not daily. ${ }^{1}$

\section{Teens ( $\geq 12$ Years Old)}

As-needed low dose ICS-formoterol combination was given as a second option under the "preferred controller" section for adolescents $\geq 12$ years old, where it may also be used as preferred reliever option as a new recommendation starting from 2019 in the GINA guidelines. ${ }^{1,9}$ The evidence for this option was provided by SYGMA 1-2 studies. ${ }^{14,15}$ This recommendation stems from the fact that the annual number of attacks and the rate of severe attacks are not-inferior in as-needed ICS-formoterol group compared to daily low dose ICS group. ${ }^{14,15}$ Although benefits of daily use of ICS (reduction in severe attacks, hospitalization and mortality) are well known, ${ }^{11,21,22}$ treatment compliance is an important issue in mild asthma. Therefore, this option may be a good choice for teens 
with poor treatment compliance. ${ }^{23}$ On the other hand, this treatment regimen is not recommended in step 2 in the NHBLI guidelines. ${ }^{10}$

At this step, NHBLI makes a new conditional recommendation of as-needed ICS and SABA used concomitantly which was given under the "other controller option" in the GINA guidelines. ${ }^{1,10}$ Supporting data comes from two studies using low dose ICS taken when SABA was taken in separate inhalers in children between 5 and 18 years old. ${ }^{16,17}$ This treatment choice when compared with a daily low dose ICS has similar effects on asthma control, asthma quality of life and frequency of asthma exacerbations, as well as infrequent side effect profiles. ${ }^{10}$ This option may be a good alternative for patients whose compliance is poor with daily low dose ICS. However, the NHBLI guidelines warns clinicians about the fact that teens with low or high perception of symptoms may not be good candidates for as-needed ICS and SABA use concomitantly. ${ }^{10}$

Subcutaneous allergen immunotherapy (SCIT) was proposed as a new conditional recommendation as adjunct treatment to standard pharmacotherapy in allergic individuals whose asthma is controlled according to the NHBLI guidelines between steps 2 and $4 .{ }^{10}$ Patients who have demonstrated allergic sensitization and evidence of worsening asthma symptoms after acute (e.g., pets), seasonal (e.g., pollens), or chronic exposure to allergens (e.g., dust mites) were stated as candidates for this treatment if they perceive a high value on possible small improvements in some aspects of asthma outcomes with tolerable side effects.

\section{6- to II-Year-Old Children}

There are two new recommendations for this age group at step 2. One is as-needed low dose ICS and SABA concomitant use in separate inhalers as described in the GINA guidelines since $2019^{1,9,16,17}$ and the other is SCIT as adjunct treatment to standard pharmacotherapy as described in the NHBLI guidelines with the same indications given in teens. ${ }^{10}$

\section{Preschool Children ( $\leq 5$ Years Old)}

There is no new recommendation in either the GINA or NHBLI guidelines for this age group at Step 2.

\section{Step 3}

Step 3 treatment is recommended for moderate persistent asthma. ${ }^{1}$ Moderate asthma is defined as daily symptoms are much more common (most days) or waking up at night due to asthma occur at least once a week in GINA guideline. $^{1}$

\section{Teens ( $\geq 12$ Years Old)}

There are two new changes at this step in GINA guideline since 2019 and NHBLI guideline. ${ }^{1,9,10}$ The first one is similar in both guidelines in the preferred reliever option as low dose ICS-formoterol for patients prescribed maintenance and reliever therapy. ${ }^{1,9}$ However, ICS-formoterol fixed combination should not be used as the reliever for patients taking combination ICS-LABA medications with a different LABA. This recommendation is made because ICS-formoterol maintenance and reliever option has been shown to significantly reduce severe attacks and provide a similar level of control compared to either fixed dose ICS-formoterol or high-dose ICS maintenance treatment plus SABA. ${ }^{24}$ The NHBLI guidelines comment that ICSformoterol maintenance and reliever option might not be necessary for patients whose asthma is well controlled with ICS-LABA combination and SABA as quick relief. On the other hand, patients with a severe exacerbation in the previous year are particularly good candidates for ICSformoterol maintenance and reliever option to reduce exacerbations depending on the evidence. ${ }^{10,25}$

Maintenance and reliever treatment is recommended either with beclometasone-formoterol ${ }^{26}$ or budesonideformoterol ${ }^{27}$ combinations in a single inhaler but studies involving children and adolescents were made with only budesonide-formoterol combinations..$^{25,28-30}$ The maximum total daily dose of formoterol used in these studies did not exceed $54 \mathrm{mcg}$ for ages 12 years and older. $^{10,25,28,29}$

The second change in the guidelines is related with specific allergen immunotherapy. In the GINA guidelines sublingual allergen immunotherapy for asthmatic patients with allergic rhinitis sensitized to house dust mite is suggested as additional treatment choice to standard treatment under "other controller options". ${ }^{1,9}$ In NHBLI guideline, sublingual immunotherapy is not recommended because Food and Drug Administration did not support the use of it for allergic asthma. ${ }^{10}$ On the other hand, NHBLI guideline makes a conditional recommendation for SCIT with pets, pollens, house dust mites for patients who are sensitized and show a clinically meaningful increase in asthma symptoms upon exposure to these allergens. ${ }^{10}$ 


\section{6- to II-Year-Old Children}

In this age group, only NHBLI guideline made a new recommendation with ICS-formoterol in a single inhaler for maintenance and reliever as the prefered option for children between 5 and 11 years old. ${ }^{10}$ There are four randomised controlled studies ${ }^{25,28-30}$ referred for this recommendation, two of which included also children younger than 11 years old. ${ }^{25,30}$ All studies found a significant decrease in severe attacks in patients using ICS-formoterol in a single inhaler for maintenance and reliever compared either to the same dose ICS-formoterol and SABA or increased dose of ICS and SABA. In addition, two of them demonstrated a better growth with ICSformoterol in a single inhaler for maintenance and reliever compared to higher dose of ICS. ${ }^{25,30}$ The guideline recommends this option with moderate certainty of evidence for children 4-11 years old. ${ }^{10}$ There is no new recommendation for this age group in the GINA guidelines at Step $3 .{ }^{1}$

\section{Preschool Children ( $\leq 5$ Years Old)}

There is a no new recommendation for this age group in the GINA guidelines, but a major new treatment option only in NHBLI guidelines in this age group. ${ }^{1,10}$ For children $\leq 3$ years old, the NHBLI guidelines showed daily low dose ICS-LABA as maintenance and SABA as preferred reliever treatment in a figure without any recommendation or explanation about it. For preschool children (4 years old) however, the NHBLI guideline recommends low dose ICS-formoterol in a single inhaler for maintenance and reliever with moderate evidence of certainty for children 5-11 years old. ${ }^{25,30}$

There is no study investigating ICS-formoterol in a single inhaler for maintenance and reliever in preschool children younger than 4 years old. There are 3 studies that used fluticasone-salmeterol combination as ICS-LABA for maintenance and SABA for quick relief that included children 5 years and younger. ${ }^{31-33}$ In the first study, it was shown that 26 weeks long fixed dose fluticasonesalmeterol combination did not differ in severe asthma exacerbations requiring hospitalization compared to the same dose fluticasone-use alone in children 4-11 years old. ${ }^{31}$ The second study included 300 children aged 8 months to 4 years in a randomized, double-blind fashion with either fixed dose fluticasone propionate $80 \mathrm{mcg} / \mathrm{sal}-$ meterol $25 \mathrm{mcg}$ combination or the same dose of fluticasone propionate for 8 weeks. ${ }^{33}$ Fluticasone propionate-salmeterol combination did not show superior efficacy in mean total asthma symptom scores to fluticasone propionate although no clinically significant differences in safety were noted with fluticasone propionate/ salmeterol usage. ${ }^{33}$ The last study, which was observational, used fluticasone propionate-salmeterol combination treatment in children younger than 5 years old with a mean duration of $12.45 \pm 9.14$ months. They showed an $89 \%$ reduction in hospitalizations, a $71 \%$ reduction in exerciserelated asthma symptoms and an $81 \%$ reduction in nocturnal asthma symptoms. ${ }^{32}$ However, the rate of ICS treatment before initiation of fluticasone-salmeterol combination was very low in this study (only 19\%), which may bias their results. Therefore, we believe that there is still no sufficient data to recommend the use of any ICS-LABA combinations as a controller in children under 4 years old. ${ }^{31-33}$

\section{Conclusion}

Both the GINA and NHBLI asthma guidelines revised the document depending on recent evidence. They mainly recommended two new treatment choices in mild to moderate childhood and adolescent asthma: ICS-budesonide in a single inhaler as maintenance and reliever and low dose ICS taken whenever SABA taken. However, these recommendations do not match with respect to treatment steps at each age group which leads to a discrepancy between these two guidelines. Guidelines may help clinicians in planning the treatments, however, interpretation of the same evidences may differ depending on different issues. Therefore, a personalized treatment strategy may be needed not only for the severe spectrum of the disease but also for mild to moderate asthma in childhood.

\section{Abbreviations}

ICS, Inhaled corticosteroids; GINA, Global Initiative for Asthma; LABA, Long-acting beta ${ }_{2}$-agonist; NHLBI, National Heart, Lung, and Blood Institute; RCT, Randomized controlled trial; SABA, Short-acting beta $2_{2}^{-}$ agonist; SCIT, Subcutaneous Allergen Immunotherapy.

\section{Disclosure}

The authors have no conflicts of interest to declare for this work.

\section{References}

1. Global Initiative for Asthma (GINA). Global strategy for asthma management and prevention (Updated 2020). Available from: www. ginasthma.org. Accessed March 10, 2021. 
2. National Asthma Education and Prevention Program. Expert Panel Report 3: Guidelines for the Diagnosis and Management of Asthma. Bethesda, Maryland: National Heart, Lung, and Blood Institute, National Institutes of Health; 2007.

3. Fitzpatrick AM, Bacharier LB, Jackson DJ, et al. Heterogeneity of mild to moderate persistent asthma in children: confirmation by latent class analysis and association with 1-year outcomes. J Allergy Clin Immunol Pract. 2020;8(8):2617-2627. doi:10.1016/j.jaip.2020.02.032

4. Howrylak JA, Fuhlbrigge AL, Strunk RC, Zeiger RS, Weiss ST, Raby BA; Childhood Asthma Management Program Research Group. Classification of childhood asthma phenotypes and long-term clinical responses to inhaled anti-inflammatory medications. J Allergy Clin Immunol. 2014;133(5):1289-300, 1300. e1-12. doi:10.1016/j.jaci.2014.02.006

5. Rodriguez-Martinez CE, Sossa-Briceño MP, Castro-Rodriguez JA. Predictors of response to medications for asthma in pediatric patients: a systematic review of the literature. Pediatr Pulmonol. 2020;55 (6):1320-1331. doi:10.1002/ppul.24782

6. Dusser D, Montani D, Chanez P, et al. Mild asthma: an expert review on epidemiology, clinical characteristics and treatment recommendations. Allergy. 2007;62(6):591-604. doi:10.1111/j.1398-9995.2007.01394.x

7. Papadopoulos NG, Čustović A, Cabana MD, et al. Pediatric asthma: an unmet need for more effective, focused treatments. Pediatr Allergy Immunol. 2019;30(1):7-16. doi:10.1111/pai.12990

8. FDA. FDA Requires Boxed Warning About Serious Mental Health Side Effects for Asthma and Allergy Drug Montelukast (Singulair); Advises Restricting Use for Allergic Rhinitis. FDA; 2020.

9. Global Initiative for Asthma (GINA). Global strategy for asthma management and prevention (Updated 2019). Avaliable from: www. ginasthma.org. Accessed March 10, 2021.

10. A report from the National Asthma Education and Prevention Program Coordinating Committee Expert Panel Working Group. 2020 Focused Updates to The Asthma Management Guidelines. National Heart, Lung, and Blood Institute, National Institutes of Health; 2020 Available from: www.nhlbi.nih.gov. Accessed March 10, 2021.

11. Suissa S, Ernst P, Benayoun S, Baltzan M, Cai B. Low-dose inhaled corticosteroids and the prevention of death from asthma. $N$ Engl J Med. 2000;343(5):332-336. doi:10.1056/NEJM200008033430504

12. Suissa S, Ernst P, Kezouh A. Regular use of inhaled corticosteroids and the long term prevention of hospitalisation for asthma. Thorax. 2002;57(10):880-884. doi:10.1136/thorax.57.10.880

13. Reddel HK, Ampon RD, Sawyer SM, Peters MJ. Risks associated with managing asthma without a preventer: urgent healthcare, poor asthma control and over-the-counter reliever use in a cross-sectional population survey. BMJ Open. 2017;7(9):e016688. doi:10.1136/ bmjopen-2017-016688

14. O'Byrne PM, FitzGerald JM, Bateman ED, et al. Inhaled Combined Budesonide-Formoterol as Needed in Mild Asthma. $N$ Engl J Med. 2018;378(20):1865-1876. doi:10.1056/NEJMoa1715274

15. Bateman ED, Reddel HK, O’Byrne PM, et al. As-Needed Budesonide-Formoterol versus Maintenance Budesonide in Mild Asthma. $N$ Engl J Med. 2018;378(20):1877-1887. doi:10.1056/ NEJMoa1715275

16. Martinez FD, Chinchilli VM, Morgan WJ, et al. Use of beclomethasone dipropionate as rescue treatment for children with mild persistent asthma (TREXA): a randomised, double-blind, placebo-controlled trial. Lancet. 2011;377(9766):650-657. doi:10.1016/S0140-6736(10)62145-9

17. Sumino K, Bacharier LB, Taylor J, et al. A pragmatic trial of symptom-based inhaled corticosteroid use in African-American Children with Mild Asthma. J Allergy Clin Immunol Pract. 2020;8 (1):176-185.e2. doi:10.1016/j.jaip.2019.06.030
18. Bacharier LB, Phillips BR, Zeiger RS, et al. Episodic use of an inhaled corticosteroid or leukotriene receptor antagonist in preschool children with moderate-to-severe intermittent wheezing. J Allergy Clin Immunol. 2008;122(6):1127-35.e8. doi:10.1016/j.jaci.2008.09.029

19. Ducharme FM, Lemire C, Noya FJ, et al. Preemptive use of high-dose fluticasone for virus-induced wheezing in young children. N Engl J Med. 2009;360(4):339-353. doi:10.1056/NEJMoa0808907

20. Svedmyr J, Nyberg E, Thunqvist P, Asbrink-Nilsson E, Hedlin G. Prophylactic intermittent treatment with inhaled corticosteroids of asthma exacerbations due to airway infections in toddlers. Acta Paediatr. 1999;88(1):42-47. doi:10.1111/j.1651-2227.1999.tb01266.x

21. Pauwels RA, Pedersen S, Busse WW, et al. Early intervention with budesonide in mild persistent asthma: a randomised, double-blind trial. Lancet. 2003;361(9363):1071-1076. doi:10.1016/S0140-6736 (03)12891-7

22. Kaiser SV, Huynh T, Bacharier LB, et al. Preventing exacerbations in preschoolers with recurrent wheeze: a meta-analysis. Pediatrics. 2016;137(6):e20154496. doi:10.1542/peds.2015-4496

23. Bitsko MJ, Everhart RS, Rubin BK. The adolescent with asthma. Paediatr Respir Rev. 2014;15(2):146-153. doi:10.1016/j.prrv.2013. 07.003

24. Jorup C, Lythgoe D, Bisgaard H. Budesonide/formoterol maintenance and reliever therapy in adolescent patients with asthma. Eur Respir $J$. 2018;51(1):1701688. doi:10.1183/13993003.01688-2017

25. O'Byrne PM, Bisgaard H, Godard PP, et al. Budesonide/formoterol combination therapy as both maintenance and reliever medication in asthma. Am J Respir Crit Care Med. 2005;171(2):129-136. doi:10. 1164/rccm.200407-884OC

26. Papi A, Corradi M, Pigeon-Francisco C, et al. Beclometasoneformoterol as maintenance and reliever treatment in patients with asthma: a double-blind, randomised controlled trial. Lancet Respir Med. 2013;1(1):23-31. doi:10.1016/S2213-2600(13)70012-2

27. Cates CJ, Karner C. Combination formoterol and budesonide as maintenance and reliever therapy versus current best practice (including inhaled steroid maintenance), for chronic asthma in adults and children. Cochrane Database Syst Rev. 2013;4:CD007313.

28. Rabe KF, Pizzichini E, Stallberg B, et al. Budesonide/formoterol in a single inhaler for maintenance and relief in mild-to-moderate asthma: a randomized, double-blind trial. Chest. 2006;129(2):2 46-256. doi:10.1378/chest.129.2.246

29. Scicchitano R, Aalbers R, Ukena D, et al. Efficacy and safety of budesonide/formoterol single inhaler therapy versus a higher dose of budesonide in moderate to severe asthma. Curr Med Res Opin. 2004;20(9):1403-1418. doi:10.1185/030079904X2051

30. Bisgaard H, Le Roux P, Bjamer D, Dymek A, Vermeulen JH, Hultquist C. Budesonide/formoterol maintenance plus reliever therapy: a new strategy in pediatric asthma. Chest. 2006;130(6):17 33-1743. doi:10.1378/chest.130.6.1733

31. Stempel DA, Szefler SJ, Pedersen S, et al. Safety of Adding Salmeterol to Fluticasone Propionate in Children with Asthma. N Engl J Med. 2016;375(9):840-849. doi:10.1056/NEJMoa1606356

32. Hatziagorou E, Kouroukli E, Galogavrou M, et al. Efficacy and safety of the combination fluticasone propionate plus salmeterol in asthmatic preschoolers: an observational study. J Asthma. 2019;56 (6):573-580. doi:10.1080/02770903.2018.1474923

33. Yoshihara S, Tsubaki T, Ikeda M, et al. The efficacy and safety of fluticasone/salmeterol compared to fluticasone in children younger than four years of age. Pediatr Allergy Immunol. 2019;30(2):19 5-203. doi:10.1111/pai.13010 


\section{Publish your work in this journal}

The Journal of Asthma and Allergy is an international, peer-reviewed open-access journal publishing original research, reports, editorials and commentaries on the following topics: Asthma; Pulmonary physiology; Asthma related clinical health; Clinical immunology and the immunological basis of disease; Pharmacological interventions and new therapies. The manuscript management system is completely online and includes a very quick and fair peer-review system, which is all easy to use. Visit http://www.dovepress.com/testimonials.php to read real quotes from published authors.

Submit your manuscript here: https://www.dovepress.com/journal-of-asthma-and-allergy-journal 